\title{
Chapter 15 \\ Towards a Structural Embeddedness of Space in the Framework of the Social Exclusion of Older People
}

\author{
Matthias Drilling, Hannah Grove, Byron Ioannou, and Thibauld Moulaert
}

\subsection{Introduction}

Social exclusion can be viewed as a component, expression or manifestation of a process by which individuals and groups become isolated from major societal mechanisms providing resources (Chakravarty and D'Ambrosio 2006). Scholars have asserted that exclusion is the outcome of the failure of specific systems that promote civic, economic, social and interpersonal participation in mainstream society, particularly in older-age (Hodge et al. 2002, Walsh et al. 2017). Thus, exclusion in older-age is multidimensional, relational, and dynamic (Atkinson 1998; Barnes et al. 2006) [also see Walsh et al. this volume for a full discussion of the attributes of exclusion in later life]. When highlighting the spatial dimension in the debate around exclusion, we must acknowledge that this spatial dimension is itself multidimensional: Older adults can be excluded from different spatial arrangements institutions, social groups, specific local benefits, or even particular events in specific places. Social exclusion is relational because it is not just about looking at a number of spatial arrangements individually (e.g. old-age residential housing units, a dementia village), but rather looking at their interlinkages between, as well

\footnotetext{
M. Drilling $(\square)$

University of Applied Sciences and Arts, School of Social Work, Institute for Social Planning, Organizational Change and Urban Development ISOS, Muttenz, Switzerland e-mail: matthias.drilling@fhnw.ch

H. Grove

Department of Geography, Maynooth University, Maynooth, Ireland

B. Ioannou

Department of Architecture, Frederick University, Nicosia, Cyprus

T. Moulaert

PACTE Social Sciences Laboratory, Université Grenoble Alpes, \& CNRS, Sciences Po Grenoble, Grenoble, France
} 
as their embeddedness, in the dominant model of society (like "successful ageing" or "active ageing") from which exclusion occurs (Silver 1994). Finally, exclusion is dynamic because it is a process that is highly conditional on time and place. As different places have different histories, cultures and institutions, they shape norms, values and, therefore, different approaches and access to resources. In conclusion, using the multidimensional concept of social exclusion put forward in this edited volume suggests that we need to think in more complex and interwoven ways, and more theoretically, about spatial exclusion of older people (Moulaert et al. 2018).

This chapter aims to address this challenge. We first introduce relevant writings that can be used to relate spatial aspects to older people's social exclusion more comprehensively; and accordingly adapt these thoughts to a model which we call the "Age, Space and Exclusion ASE-Triangle". We then identify new pathways for empirical research and present two case studies (Greater Dublin - Ireland, and Nicosia-Cyprus) to explore the possibilities and limits of applying the ASE-Triangle to empirical work. The conclusion then situates our model within existing literature.

\subsection{Triadic Thinking - Trans-Disciplinary Theorizing of Spatial Exclusion}

The debate about age, space and exclusion is usually tied to the epistemological objectives of a discipline. Human geography has the longest tradition of exploring spatial concepts, and the 'humanistic turn' in the 1970s freed the discipline from its basic positivist attitudes towards an understanding of 'space' from a subjective and micro-geographical perspective (Drilling and Schnur 2019). At almost the same time, French-speaking sociology intensified its debate around 'space', orientating itself to Lefebvre who maintained "that space must be understood not simply as a concrete, material object, but also as an ideological, lived, and subjective one." (Warf and Arias 2009 , p. 3). These discussions were supported by other disciplines such as philosophy. Casey (2000/1987) bridged the gap to 'place'-concepts, when he differentiated between 'locus' and 'place', describing the latter as selective for memories and related to the body. "In the end, we can move into place, indeed be in a place ..." (Casey 2000/1987, p. 189). In the following years the focus of these new pathways in space-related research varied enormously and embraced studies on space and identity, on places as centres of meaning constructed out of lived experience, or on space as a process that forms and shapes itself along perceptions and attributions, filled with opinions that can run across objective concepts such as life situations, milieus or age groups (detailed in Drilling and Schnur 2019). In geography, a sub-discipline of geographical gerontology arose, defining places as "the context in which we live, settings, to which we feel attached but which also shape our experience of social processes, such as the provision of health care, the process of ageing, or social and economic restructuring." (Wiles 2005, p. 101).

The call for gerontology to be the key interdisciplinary frame to guide agerelated questions to become more spatial is still relevant. Despite that "place is now a central concept within national and international ageing policy" (Urbaniak and Walsh 2019, p. 1), scholars like Moulaert or Wanka still state that gerontology 
"tends to ignore longstanding traditions of researching spatial exclusion in other disciplines..." (Moulaert et al., p. 11) and "often shares a positivistic understanding of space" (Wanka et al. 2018, p. 25).

But how to combine a relational theory of space with a concept of social exclusion in later life? We propose a starting point in the vision of space as a simultaneity of the material, the social and the symbolic as developed by Henri Lefebvre. In Lefebvre's work, cities and neighbourhoods are understood as constantly changing human relational structures that are regulated by political, social and economic conditions (Lefebvre 1991). The space is thus designed as a product of dynamic relations between materialisations (spatial practice/perceived space), conceptions (representations of space/conceived space) and experiences (representational spaces/lived space).

- Spatial practice (perceived space) derives, for example, from non-reflexive daily routines that are affected by the built neighbourhood and infrastructures, all of them located in specific sites. These structures that can be physically touched, navigated to or frequented, lead to specific individual perceptions and actions. How older people with differing lifestyles and concepts of life perceive environments and other people and how they act in their environments is influenced by age stereotypes that are inherent to spatial practices.

- Representations of space (conceived space) are a result of the knowledge society with its policy makers, architects, planners, developers or administration, as well as their concepts, maps, plans, models and designs. All these stakeholders have their own ideas and convictions as to what ageing means (or should mean). Such representations are laden with ideologies.

- Representational space (lived space) refers to passively, rather than actively (see above), experienced space - the way people subconsciously read and understand signs and symbols in space. These symbols help us to tell a road from a footpath or a playground from a park, but they also give us clues about where we can and cannot go, for example via signs of disorder that might symbolise crime in a certain area.

Applying such a lens to the relations between old-age, space and exclusion, results in a concept that prompts us to interpret every observation as an expression of a triadic relationship. However, it's not only space, but also age and exclusion that can be perceived, conceived, and lived. Like the triangulation of space, a triangulation of age and exclusion exists: modern neuroscience, for example, explains what it means to live with dementia (conceived age). Families feel insecure and believe that dementia villages offer optimum safety. Those who can afford it rent space there for their relatives; those who cannot afford it are left behind (perceived exclusion). Scholars label such neighbourhoods as 'geriatric ghettos' (conceived exclusion); older people read stories about their built environment in the newspapers and fear leaving their home (lived exclusion).

This interplay between different forms of perceiving, living and conceiving space, age and exclusion- depending on the power relations in society at a given time results in narratives and paradigms used to analyse the older person in their environment and formulate recommendations for policy areas (such as the WHO "age-friendly cities" strategy). In this model space is considered to encompass an objective set of characteristics and a set of subjective elements, where it is imbued with meaning in the context of ageing and exclusion. As such we recognise the links between space and place in our interpretation, and accordingly use the terms interchangeably. 
Figure 15.1 presents the ASE (Age, Space, and Exclusion) triangle derived from such a triadic thinking.

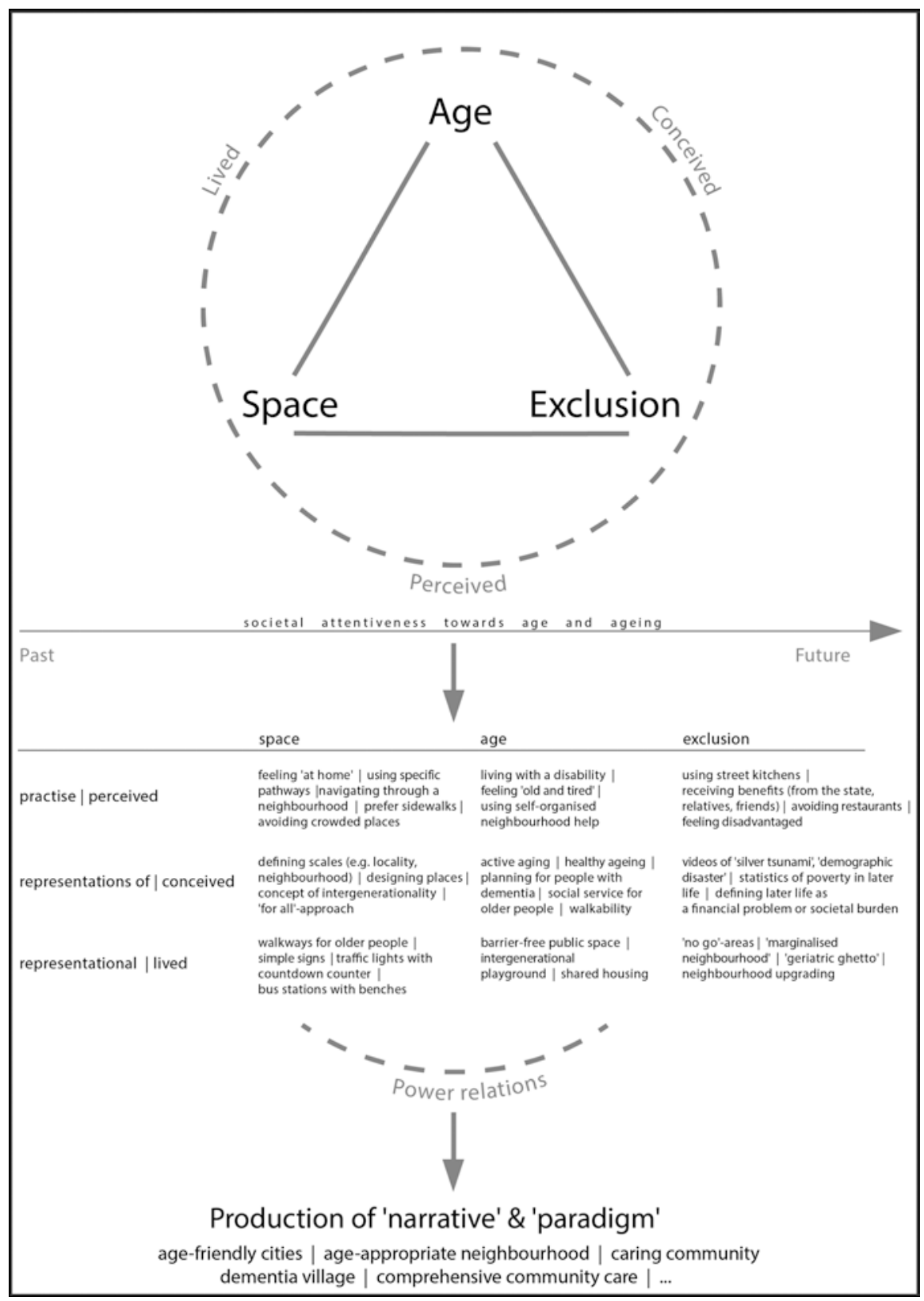

Fig. 15.1 How space, age and exclusion produces political narratives and paradigms - the "Age, Space and Exclusion ASE-Triangle" 
After presenting our "Ageing, Space and Exclusion - ASE Triangle", the following section illustrates the interplay between space, age and exclusion using two examples: Greater Dublin (Ireland) and Pallouriotissa/Nicosia (Cyprus).

\subsection{Ageing in Greater Dublin/Ireland: Experiences of Local Exclusion in Daily Life}

Based on an on-going $\mathrm{PhD}$ project (Grove, n.d.) that explores whether older people's local environments support residents to 'age well', this case study uses a 'Qualitative GIS' approach, which integrates both qualitative and spatial data, and emphasises the importance of including meaning within mapping (Cope and Elwood 2009; Milton et al. 2015; Meijering and Weitkamp 2016). Twenty-four interviews and mapping exercises were carried out with 34 older people aged between 66 and 89 years old in a suburban and inner-city study area in Greater Dublin. 'Go-along' interviews were also conducted with 20 of the participants. The results, presented here as an illustrative case, focus on an example of spatial exclusion from the project area, and the impact this is having on one of the participants. The ASE triangle model is applied to this example to think through how spatial practices, representational space, and representations of space all interact to produce different forms of spatial exclusion.

During interviews for this research, Anne (a pseudonym) shared that she was very distressed as a result of a new development happening in her local area.

There were several reasons for this distress. First, Anne was upset that she would lose her views of the mountains from her garden to the rear of her house as the development would create a significant obstruction. Anne highly valued these views which were a part of the characteristics of her home environment and which she had enjoyed for over 40 years. Second, Anne was concerned about safety as a result of the construction and completion of this new development. This related to both the building of a temporary alleyway to facilitate mobility through the neighbourhood during the development, and the intention to build a permanent lane at the back of her house.

For Anne, the imposed structures have created/will create potential spaces for antisocial behaviour hidden from external view and have further contributed to Anne not feeling safe in her neighbourhood. During her interview and go-along interview, she raised concerns about the behaviour of her neighbours, and how some of the newer residents did not seem to care about their local environment and would leave rubbish everywhere. She was also worried about people

\footnotetext{
${ }^{1}$ The Greater Dublin Area encompasses Dublin City and the six administrative counties (local authorities) of Fingal, Dun Laoghaire-Rathdown, South Dublin, Kildare, Meath and Wicklow.
} 
jumping over the fence into her garden, affecting her sense of safety in her own home:

'Our lane was closed off, so that was ok. But these are leaving the lane as a walkthrough and... well, in the 80 s we all had lanes behind the houses. But there was only unsociable... activity in them, so we fought and we got them all closed up. Now these [developers] are opening this up, and I was a young woman at that stage, now I'm 70 and they're bringing this on us.' (Main Interview)

Third, and linked to the construction of the temporary alleyway and her perceived lack of safety, Anne spoke about difficulties in maintaining social participation and connections with her trusted neighbours and friends in the area. A valued part of Anne's routine is to visit her friend's house. The usual route she takes is shown in Fig. 15.2 below (dotted green line), but the new alleyway has been created with tall fencing which makes it very dark, and there is a 'blind corner' where you can't see who is on the other side. Although it remains the most direct route, Anne no longer feels safe walking through it, and so in her mind it might as well not be there because she would not use it, and instead she is forced to walk a much longer route. From her perspective, she is more physically disconnected from her friend than she was before and describes this as an 'awful inconvenience':

'Oh I wouldn't go through that lane... oh my God... you see the way it's blocked off there, it's all black. Well then when you go up that lane it's completely black. Now, it's only going to be, I think, a temporary thing while they're building. But, the thing about it is, it's an awful inconvenience...' (Main Interview).

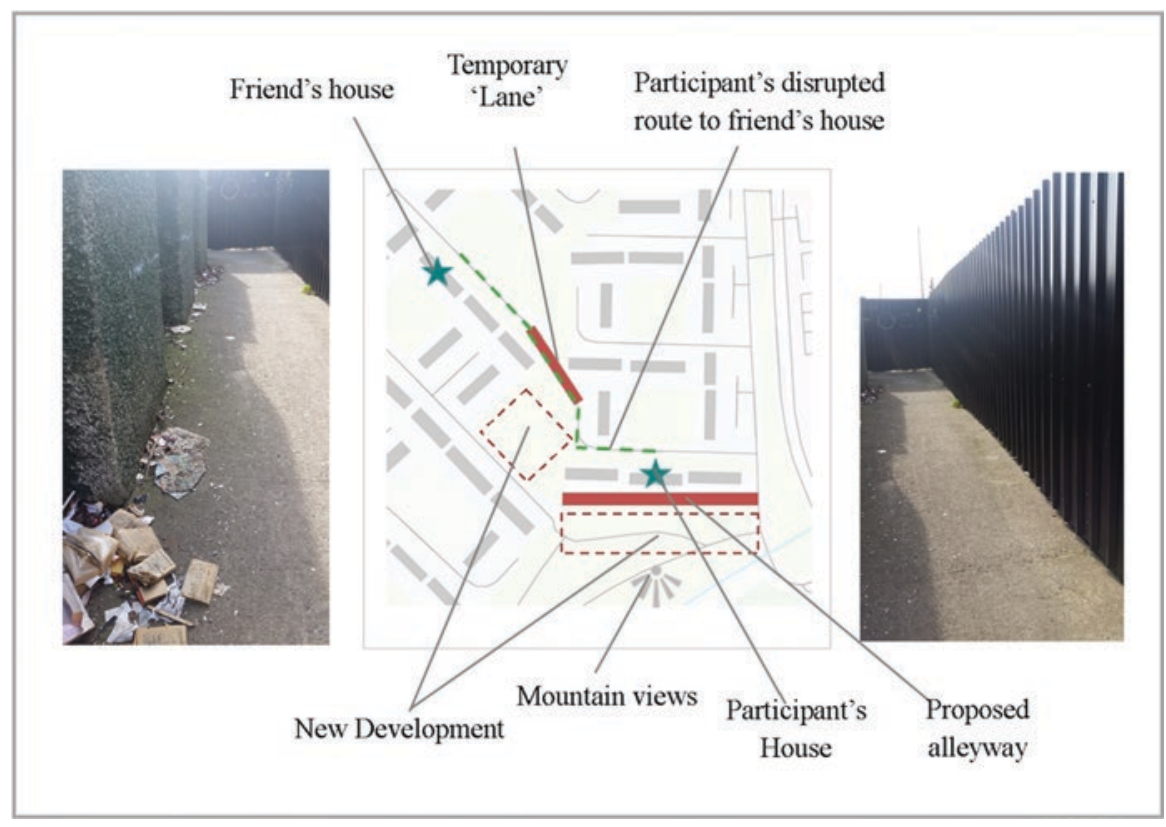

Fig. 15.2 Annotated map of participant's local environment (photographs taken by researcher during 'go-along' interview) 
Turning now to triadic thinking: with regard to spatial practices, Anne's routes and routines have been disrupted by the temporary alleyway. To get to her friend's house, she previously had to walk a very short distance through a green space (less than $5 \mathrm{~min}$ ), but now she has to 'go all around' the estate and walk over $10 \mathrm{~min}$. This example reinforces that in order to better understand accessibility and forms of spatial exclusion for older people, there is a need to not just consider objective or physical distances to and from a place, but to also include more subjective components which may influence older adult behaviour. This may include perceived barriers about what a reasonable distance may be for an individual based on existing capabilities or habits, or perceptions of safety whilst navigating their local environment.

Closely connected to spatial practices, the notion of representational space leads to situations of social exclusion. Anne associated both the lane and the litter present in the lane with anti-social behaviour. The fact that there was no litter before the lane and now there is, introduces both the fear and confirmation of anti-social behaviour to this participant, which in turn creates an unwillingness to walk along the lane:

'And look at that, there's rubbish. That was never here. They're after creating more problems. Big change that I can see. Litter... It's too dangerous, you know.' (Go-along interview).

The fear around this lane also represents wider fears that the participant has about some of her neighbours, and about who might move into the new housing and whether she will be safe: 'Who's going to get them [the new houses]? They can get over your back wall. Depending on who it is.' (Go-along interview).

Finally, this example highlights that these considerations have perhaps not been taken into account during the planning phase, and illustrates the impact of a lack of consultation with residents, particularly older residents, concerning how to minimise disruption during this development. There are representations of space that show this site as a future development area or suburban infill development. In this instance it is represented as a map on a planning application for this development. This is the dominant representation, but perspectives of older people, and their subjective experiences and fears are absent from this traditional form of mapping.

By understanding older people's spatial practices and the meaning that they place on various signs and visual cues in the built environment, we can highlight everyday forms of spatial exclusion. These may also differ or contrast with policymakers' and professionals' experiences or understanding of the same place.

Within the broader study, many other narratives referred to other spatial and civic exclusion processes. For example, another participant was unable to walk through a green space shortcut to her community centre due to health and security challenges, and limited public transport and local shopping options meant that daily errands such as buying groceries and going to the doctor had become a challenge. Table 15.1 illustrates the three dimensions of older people's experiences of place-related exclusion identified in this case. 
Table 15.1 Dominant patterns between age, space and exclusion in Greater Dublin

\begin{tabular}{|c|c|c|c|}
\hline & Age & Space & Exclusion \\
\hline Practices & $\begin{array}{l}\text { - How people } \\
\text { 'practise' and } \\
\text { experience ageing } \\
\text { varies } \\
\text { (heterogeneity of } \\
\text { older adults). }\end{array}$ & $\begin{array}{l}\text { - Routines, daily } \\
\text { activities. } \\
\text { - Dependent on age } \\
\text { (and mobility and } \\
\text { health), and can in turn } \\
\text { create either inclusion } \\
\text { or exclusion when } \\
\text { ageing in place. } \\
\text { - Physical barriers/ } \\
\text { enablers. }\end{array}$ & $\begin{array}{l}\text { Physical practices of } \\
\text { exclusion - e.g. lack } \\
\text { of public transport, or } \\
\text { no community centre. }\end{array}$ \\
\hline $\begin{array}{l}\text { Representations of } \\
\text { (Of which policy is one } \\
\text { form, but older adult } \\
\text { representations are also } \\
\text { needed). Some are more } \\
\text { dominant than others. }\end{array}$ & $\begin{array}{l}\text { - Dominant forms. } \\
\text { - Types of 'ageing } \\
\text { well' (successful, } \\
\text { healthy, happy, } \\
\text { active, positive). } \\
\text { - 'Harder to reach' } \\
\text { older adult } \\
\text { subgroups not as } \\
\text { well represented. }\end{array}$ & $\begin{array}{l}\text { - Policymakers maps } \\
\text { are dominant } \\
\text { representations of } \\
\text { space. } \\
\text { - Qualitative GIS + } \\
\text { go-along interviews } \\
\text { help to make } \\
\text { subjugated perspectives } \\
\text { and experiences of } \\
\text { place more visible. }\end{array}$ & $\begin{array}{l}\text { - Raising awareness of } \\
\text { forms of exclusion and } \\
\text { inclusion. } \\
\text { - Some older people } \\
\text { can be so excluded } \\
\text { they are not even } \\
\text { represented; specific } \\
\text { research } \\
\text { methodologies can be } \\
\text { a tool to resist this. }\end{array}$ \\
\hline Representational & $\begin{array}{l}\text { - Subjective } \\
\text { experiences of } \\
\text { ageing. }\end{array}$ & $\begin{array}{l}\text { - Subjective/Meaningful } \\
\text { (more place). } \\
\text { - Influenced by what is } \\
\text { important to } \\
\text { individual - can also } \\
\text { lead to more perceived } \\
\text { barriers/enablers. }\end{array}$ & $\begin{array}{l}\text { - Subjective aspects of } \\
\text { exclusion (perceived } \\
\text { exclusion), e.g. } \\
\text { rubbish. }\end{array}$ \\
\hline
\end{tabular}

\subsection{Ageing in the Pallouriotissa Suburbs, Nicosia/Cyprus: Suburbs as Both a Problem and Solution to Spatial Exclusion}

This case study is based on the first results of research carried out by Frederick University (Ioannou 2018) that outlined the spatiality of ageing in the suburban context of Cyprus, in particular in the Pallouriotissa district that has undergone continuous suburban expansion during the last 80 years. Field data was derived from semi-structured interviews with 20 older people aged between 65 and 80 years old, car drivers and homeowners of Cypriot origin, which is the predominant group among the ageing population of Cyprus. Interviews were structured around the World Health Organisation (WHO 2015) age-friendly indicators most associated with the concepts of suburban development in Cyprus, specifically: walkability, accessibility of public spaces, and accessibility of public transport. Additionally, 
field observation provided a comparative assessment of human presence and quality of space and infrastructures. The aim of the approach was to investigate agefriendliness in terms of how the particular neighbourhood settings affect everyday lives.

The ASE triangle model is applied to this example to think through how representations of space influence perceptions of feeling old (perceived age) in place, and how these perceptions change during the different urban design epochs of Nicosia. This brings awareness that the ASE triangle is embedded in time and influenced by societal attentiveness towards age and ageing (see Fig. 15.1 'past and future' line).

The Pallouriotissa urban district is a very diverse place, with an old quarter dating to the Ottoman period and residential areas encompassing almost a century of suburban history in Nicosia through four distinct subareas (Fig. 15.3):

1. initial old quarter (Ottoman period); mixed use, irregular, narrow streets, compact fabric;

2. early suburbia (1940s-1970s); mixed use, medium/low density, shaped suburban fabric;

3. postcolonial suburbia (1980s-1990s); medium/low density, shaped suburban fabric;

4. late suburbia (2000s-2010s); very low density, incomplete suburban fabric.

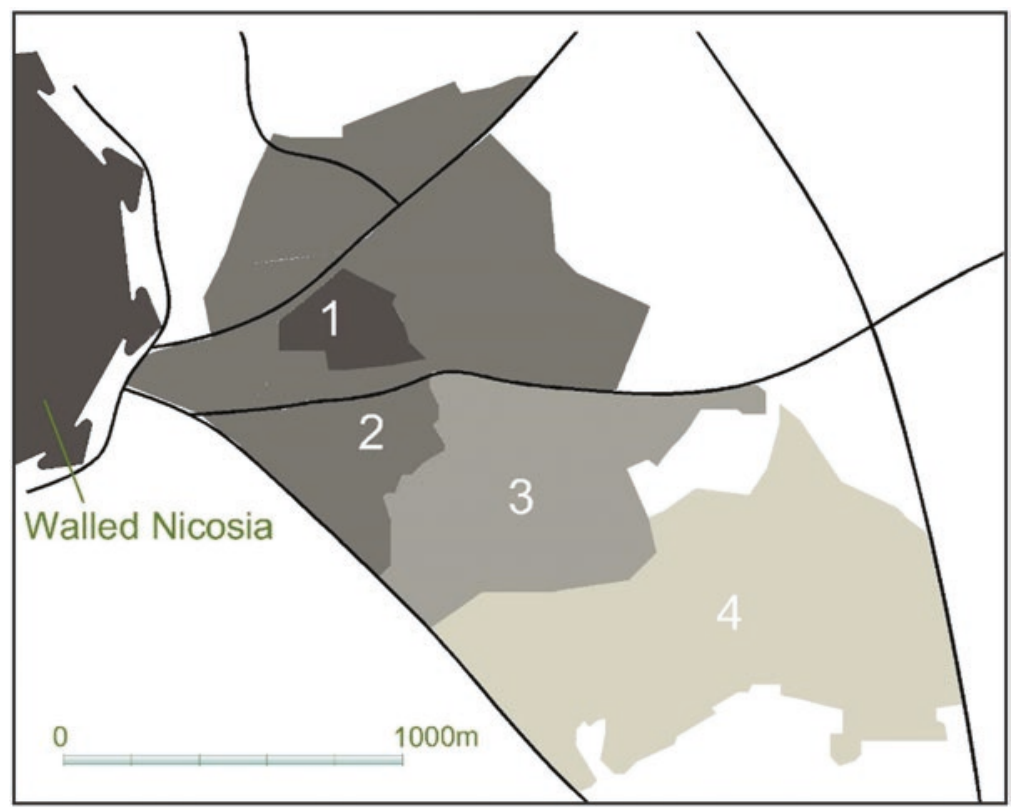

Fig. 15.3 Pallouriotissa urban district: Subareas 1-4 
All four subareas are geographically and spatially shaped by the daily movements of their various resident groups, but mainly by the ageing group that spends most of its time at home.

The initial old quarter was perceived as a run-down area by the study participants due to the condition of the buildings, despite their architectural value as heritage structures. Place attachment is high, since most of the interviewees were born and grew up there. Place appropriation is also high, since they spend time gathering in places, such as their church or their old traditional cafes. But the general satisfaction with their place of living is low because of the complex traffic flows and the low levels of care invested in the public spaces, which together do not allow older people to benefit from the compact neighbourhood structure (Fig. 15.4).

'This place is like an old village in the city, though is very hard and dangerous to move.' (Interview)

The interviewees appreciated early suburbia because it combines its green and suburban character, which is a positive stereotype, with centrality and proximity to amenities. Place attachment is high, since most of the interviewees moved there during their youth. Place appropriation is high since they live close to relatives and old friends. There is a high satisfaction with their place of living in general.

'I bought this plot just when I migrated from my village during 1960s. It's green and quiet, My daughter has built the upper floor.' (Interview)

The postcolonial suburbia was also appreciated by the interviewees due to its suburban character. Place attachment is high, since most of the interviewees moved there during their youth or early adulthood. Place appropriation is high since they live close to relatives and old friends. Their overall satisfaction with their place is again high.

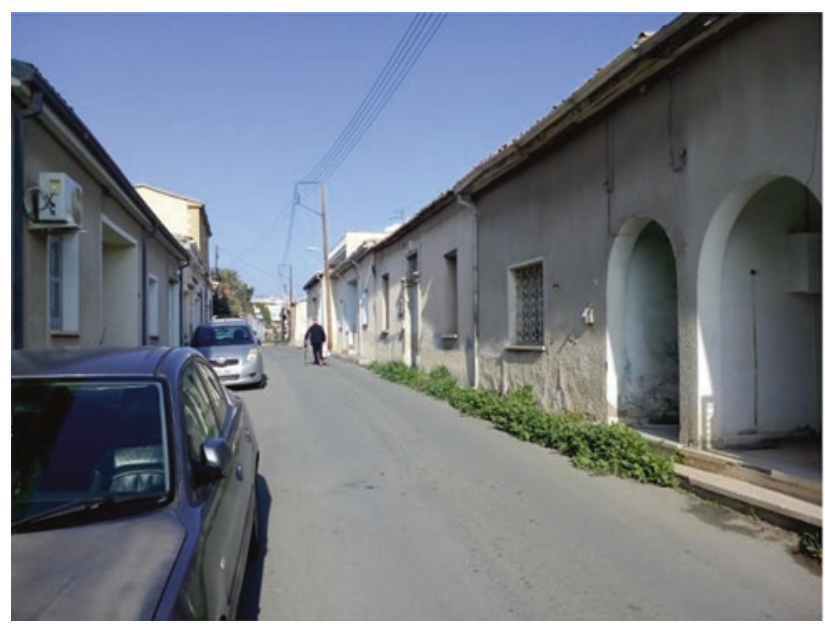

"This place is like an old" village in the city, though is very hard and dangerous to move." (Interview)

Fig. 15.4 Pallouriotissa initial old quarter street view 


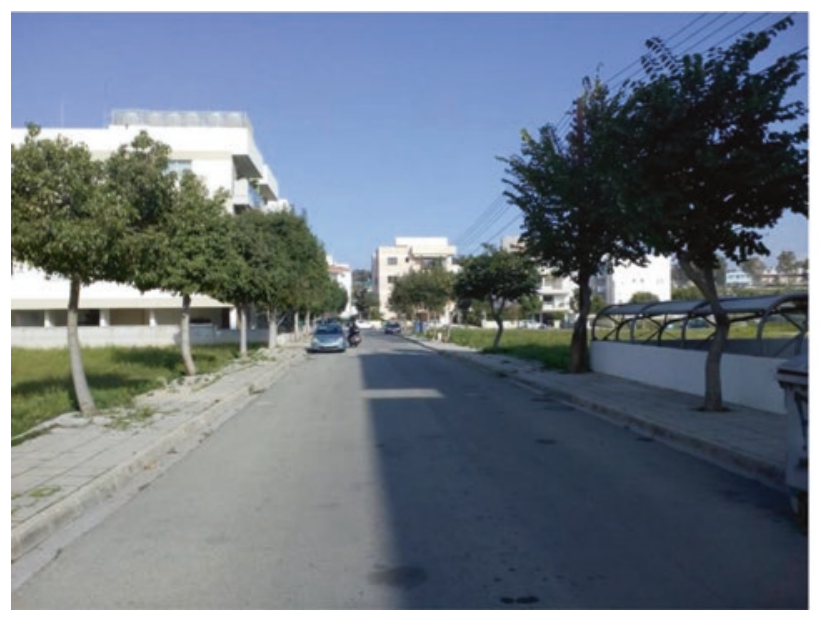

"Open sky, plenty of

parking places, and quieter than our previous place."

(Interview)

Fig. 15.5 Late suburbia street view

Late suburbia (Fig. 15.5) was appreciated by the interviewees due to its new buildings and quietness. Place attachment is low, since most of the interviewees moved there during their middle or late age. Place appropriation is low since they are effectively newcomers. Despite this fact, their overall satisfaction with their place is high: 'Open sky, plenty of parking places, and quieter than our previous place.' (Interview)

After gathering the interview data and observations in Pallouriotissa/Nicosia and analysing it using Fig. 15.1, Table 15.2 presents the three dimensions of older people's spatial experiences. In this case, however, and because of the age-friendly focus of the original study, we have structured the presentation according to the WHO indicators.

Regarding the Age aspects, the case study isolated the active and healthy ageing group (conceived age, see Fig. 15.1), setting as determining factors the attributes of space and exclusion in the urban environment. Residential mobility seems to be low in all cases, except late suburbia, but the perspective of ageing in place is high for all areas due to the supportive framework at the national level. The interviewees in the suburban sub-areas did not perceive exclusion as a visible threat. Exclusion may exist if they face any kind of disability, since the urban fabric is not adequately equipped for these cases.

On the other hand, in the initial quarter/compact neighbourhood, residents felt excluded by its differentiated fabric, both for the practical reasons previously mentioned, but also due to the perception of their place by others. Place seems to both define and be defined by age and exclusion constraints. Perception of place proves to be highly important. The initial old quarter area retained a number of virtues, like scale, proximity to amenities, character and compactness, which in the end are not much appreciated. 
Table 15.2 Dominant patterns of age, space, and exclusion in Pallouriotissa/Nicosia structured by WHO indicators

\begin{tabular}{|c|c|c|c|c|}
\hline & Initial old quarter & Early suburbia & $\begin{array}{l}\text { Postcolonial } \\
\text { suburbia }\end{array}$ & Late suburbia \\
\hline \multicolumn{5}{|l|}{ AGE } \\
\hline $\begin{array}{l}\text { Population } \\
\text { (No.) }\end{array}$ & 291 & 2682 & 1608 & 2204 \\
\hline $\begin{array}{l}>65(\% \text { of } \\
\text { total) }\end{array}$ & 30 & 20 & 19 & 7 \\
\hline \multicolumn{5}{|l|}{ SPACE } \\
\hline $\begin{array}{l}\text { Indicator: } \\
\text { walkability }\end{array}$ & $\begin{array}{l}\text { - Limited space } \\
\text { for pedestrians. } \\
\text { Limited benches. } \\
\text { - Low } \\
\text { attractiveness of } \\
\text { routes. } \\
\text { - Narrow and } \\
\text { interrupted } \\
\text { footpaths. } \\
\text { - Walking for both } \\
\text { leisure and } \\
\text { service. } \\
\text { - Partly car } \\
\text { dependent. }\end{array}$ & $\begin{array}{l}\text { - Some space for } \\
\text { pedestrians. No } \\
\text { benches. } \\
\text { - Medium } \\
\text { attractiveness of } \\
\text { routes - traffic. } \\
\text { - Narrow and } \\
\text { interrupted } \\
\text { footpaths. } \\
\text { - Walking for both } \\
\text { leisure and } \\
\text { service. } \\
\text { - Car dependent. }\end{array}$ & $\begin{array}{l}\text { - Some space for } \\
\text { pedestrians. No } \\
\text { benches. } \\
\text { - Low } \\
\text { attractiveness of } \\
\text { routes - traffic. } \\
\text { - Narrow and } \\
\text { interrupted } \\
\text { footpaths. } \\
\text { - Walking mostly } \\
\text { for leisure. } \\
\text { - Car dependent. }\end{array}$ & $\begin{array}{l}\text { - Adequate space } \\
\text { for pedestrians. } \\
\text { No benches. } \\
\text { - High } \\
\text { attractiveness of } \\
\text { routes - no traffic. } \\
\text { - Footpaths of } \\
\text { adequate } \\
\text { width - } \\
\text { incomplete } \\
\text { network. } \\
\text { - Walking only for } \\
\text { leisure. } \\
\text { - Exclusively car } \\
\text { dependent. }\end{array}$ \\
\hline $\begin{array}{l}\text { Indicator: } \\
\text { infrastructures }\end{array}$ & $\begin{array}{l}\text { - Green and } \\
\text { shade: limited. } \\
\text { - Streets and } \\
\text { footpaths: cared } \\
\text { for but narrow. }\end{array}$ & $\begin{array}{l}\text { - Green and } \\
\text { shade: adequate. } \\
\text { - Streets and } \\
\text { footpaths cared } \\
\text { for. }\end{array}$ & $\begin{array}{l}\text { - Green and } \\
\text { shade: adequate. } \\
\text { - Streets and } \\
\text { footpaths cared } \\
\text { for. }\end{array}$ & $\begin{array}{l}\text { - Green and } \\
\text { shade: limited. } \\
\text { - Streets and } \\
\text { footpaths: cared } \\
\text { for and sufficient. }\end{array}$ \\
\hline \multicolumn{5}{|l|}{ EXCLUSION } \\
\hline $\begin{array}{l}\text { Indicator: } \\
\text { accessibility }\end{array}$ & $\begin{array}{l}\text { Adequate foot } \\
\text { access to retail, } \\
\text { services and } \\
\text { amenities. }\end{array}$ & $\begin{array}{l}\text { Adequate foot } \\
\text { access to retail, } \\
\text { services and } \\
\text { amenities. }\end{array}$ & $\begin{array}{l}\text { Medium foot } \\
\text { access to retail, } \\
\text { services and } \\
\text { amenities. }\end{array}$ & $\begin{array}{l}\text { Difficult foot } \\
\text { access to retail, } \\
\text { services and } \\
\text { amenities. }\end{array}$ \\
\hline $\begin{array}{l}\text { Indicator: } \\
\text { human } \\
\text { presence }\end{array}$ & Moderate & Moderate & Moderate & Low \\
\hline $\begin{array}{l}\text { Indicator: } \\
\text { social contacts }\end{array}$ & $\begin{array}{l}\text { Moderate to } \\
\text { inadequate }\end{array}$ & Moderate & Moderate & Satisfactory \\
\hline
\end{tabular}

Late suburbia was lacking in the assessed dimensions but fell into the positive stereotype of newly built, low-density suburbia. Suburban subareas provide numerous and more amenable on-street parking places in close proximity to every dwelling. Older adults can use cars with limited traffic and parking stress. Parking difficulty was a very significant and frequent issue that prevents social contact and servicing. In the end, proximity did not equate to access.

Planning and urban design perceptions about 'age-friendly places' needed to become more informed about exclusion causes: how could the ASE triangle explain 
such exclusion processes? In the case study, where older adults of Pallouriotissa are car-dependent and active commuters, the attribute of accessibility and ease of car use was dominant. In many cases, it could define the range of older people's daily social contacts or even their level of happiness. Exclusion was perceived as the prevention of self-servicing or the loss of the lifestyle and commuting habits of the residents' early lives. On the other hand, older adults with disabilities could be excluded in the same way, regardless of the subarea they live in. Therefore, in the case of the initial old quarter area, space would not maintain its exclusive negative content, if age attributes were defined differently. Under this focus, age and exclusion may create a different perception or assessment of exactly the same place. Place assessment on the other hand has to consider the gravity of each indicator, especially those that vary for each user group. In this case in particular, the ease of car use is much more highly appreciated than all the other spatial aspects together.

\subsection{Conclusion}

There is no spaceless ageing and every placing of an (older) person has effects on their daily life. This chapter focuses on this interdependence, not simply limiting space to its physical dimensions. Such a concept is too narrow from our point of view and leads to a neglect of any spatial dimension beyond Euclidian definitions. In the case studies presented, space is also an emotional and social category. Places are actively visited, but the pathways planned for older people tend to be avoided by them. Objective reasons are never decisive in themselves.

In our analysis, we attempt to 'upgrade space' as a theory-led idea. Clearly, such a perspective has already been presented, for example in some of the seminal work within human geography (Rowles 1978). However, while Rowles continuously explored the "meaning of space" in an accurate and useful way for exploring new avenues in gerontology, his contribution rarely refers to critical (French/German) theory. Very interestingly, his perception of space, for older people at home, as a "surveillance zone" (Rowles 1981) does not refer to Foucault's panopticon; or, more recently, his interpretation of space as "habituation" of (little) changes in the meaning of place (Rowles 2000) neglects the "habitus" concept of Bourdieu. By referring to Lefebvre, our model clearly took the potential of such critical thinkers, i.e. the capacity to take into account the "meaning" of space as we age (as explored by Rowles), and simultaneously assumes contradictory conceptions of space. This is efficiently described within the first case study where the perception of space by Anne, due to the new development, is compared to the neglect of older people's perceptions during the planning phase of such development, in Greater Dublin.

In so doing, we clearly follow a similar avenue as the one suggested by Andrews and his colleagues (Andrews et al. 2013), i.e. contributing to a more complex and relational conception of space/place and age. While Andrews and his colleagues explores the crossings of "environmental gerontology" and of "geographical gerontology", they also acknowledge the general "spatial turn" in health and social sciences and the 
consequence of placing a higher importance on communities and the environment. Challenging the "static" vision of space and place in research, their model explores the potential of affects, following the human geography discipline. While affects are not central in our model, they nevertheless are part of the perceived space described in our two case studies. But most important, while Andrews and colleagues refer to public policies, they insist on the importance of global models of place and aging, like the WHO "age-friendly cities" strategy and indicators, to take better account of qualitative aspects of spatial life, like affects, to understand local variabilities. In our Cyprian example, the ASE Triangle directly helps to identify the limits of such indicators, where little attention is given to exclusion as a process. Therefore, in this case in the initial old quarter area, space would not maintain its exclusive negative content, if age attributes were defined differently. With such an example, we also admit that both our cases studies concern cities and their processes of suburbanization.

By arguing for a theoretically-based model inspired by critical thinkers, we hope to have contributed to a more complex and relational understanding of not only the "experience" of space, but of space and exclusion and the plurality of mechanisms that construct such experiences (i.e. "representation of space" and "space of representation"). We hope that international gerontology will benefit from our challenging model.

\section{Editors' Postscript}

Please note, like other contributions to this book, this chapter was written before the COVID-19 pandemic of 2020. The book's introductory chapter (Chap. 1) and conclusion (Chap. 34) consider some of the key ways in which the pandemic relates to issues concerning social exclusion and ageing.

\section{References}

Andrews, G. J., Evans, J., \& Wiles, J. L. (2013). Re-spacing and re-placing gerontology: Relationality and affect. Ageing \& Society, 33(8), 1339-1373.

Atkinson, A. (1998). Social exclusion, poverty and unemployment. In: A. Atkinson, \& J. Hills, (Eds.), Exclusion, employment and opportunity (pp. 1-20). STICERD, London School of Economics Discussion Papers Series CASE/4.

Barnes, M., Blom, A., Cox, K., Lessof, C., Walker, A. (2006). The social exclusion of older people: Evidence from the first wave of the English Longitudinal Study of Ageing (ELSA). London, Office of the Deputy Prime Minister, Social Exclusion Unit.

Casey, E. S. (2000/1987). Remembering. A phenomenological study (2nd ed.). Bloomington: Indiana University Press.

Chakravarty, S. R., \& D'Ambrosio, C. (2006). The measurement of social exclusion. Review of Income and Wealth, 52(3), 377-398.

Cope, M., \& Elwood, S. (2009). Qualitative GIS: A mixed methods approach. Thousand Oaks: Sage.

Drilling, M., \& Schnur, O. (2019). Neighbourhood research from a geographical perspective. DIE ERDE - Journal of the Geographical Society of Berlin, 150(2), 48-60.

Grove, H., (n.d.) Exploring the everyday experiences of older people in Greater Dublin: A qualitative GIS approach. $\mathrm{PhD}$ thesis, Maynooth University, Maynooth. 
Hodge, I., Dunn, J., Monk, S., \& Fitzgerald, M. (2002). Barriers to participation in residual rural labour markets. Work, Employment \& Society, 16(3), 457-476.

Ioannou, B. (2018). Concepts of suburban development in Cyprus: the spatiality of ageing. In Constructing an Urban Future. The spatiality and resilience of cities - infrastructures, communities and architectures, March 18-19, 2018, Abu Dhabi University (UAE). http:// architecturemps.com/wp-content/uploads/2019/01/AMPS-Proceedings-13-Constructing-anUrban-Future.pdf

Lefebvre, H. (1991). The social production of space. Oxford: Blackwell.

Meijering, L., \& Weitkamp, G. (2016). Numbers and narratives: Developing a mixed-methods approach to understand mobility in later life. Social Science \& Medicine, 168, 200-206.

Milton, S., Pliakas, T., Hawkesworth, S., Nanchahal, K., Grundy, C., Amuzu, A., Casas, J. P., \& Lock, K. (2015). A qualitative geographical information systems approach to explore how older people over 70 years interact with and define their neighbourhood environment. Health \& Place, 36, 127-133.

Moulaert, T., Wanka, A., \& Drilling, M. (2018). The social production of age, space and exclusion: Towards a more theory-driven understanding of spatial exclusion mechanisms in later life. Sociální studia/Social Studies., 1(2018), 9-23.

Rowles, G. D. (1978). Prisoners of space? Exploring the geographical experience of older people. Boulder: Westview Press.

Rowles, G. D. (1981). The surveillance zone as meaningful space for the aged. The Gerontologist, 21(3), 304-311.

Rowles, G. D. (2000). Habituation and being in place. The Occupational Therapy Journal of Research, 20(1_suppl), 52S-67S.

Silver, H. (1994). Social exclusion and social solidarity: Three paradigms. International Labour Review, 133(5-6), 531-578.

Urbaniak, A., \& Walsh, K. (2019). The interrelationship between place and critical life transitions in later life social exclusion: A scoping review. Health \& Place, 60, 102234.

Walsh, K., Scharf, T., \& Keating, N. (2017). Social exclusion of older persons: A scoping review and conceptual framework. European Journal of Ageing, 14(1), 81-98.

Wanka, A., Moulaert, T., \& Drilling, M. (2018). From environmental stress to spatial expulsion Rethinking concepts of socio-spatial exclusion in later life. International Journal of Ageing and Later Life, 12(2), 25-51.

Warf, B. \& Arias, S. (ed.) (2009). Introduction. In B. Warf, \& S. Arias (Eds.), The spatial turn. Interdisciplinary perspectives (pp. 3-10). London: Routledge.

Wiles, J. (2005). Conceptualizing place in the care of older people: The contributions of geographical gerontology. International Journal of Older People Nursing, 14(8), 100-108.

World Health Organization. (2015). Measuring the age friendliness of cities. A guide to using core indicators. Geneva: WHO Library Cataloguing-in-Publication Data.

Open Access This chapter is licensed under the terms of the Creative Commons Attribution 4.0 International License (http://creativecommons.org/licenses/by/4.0/), which permits use, sharing, adaptation, distribution and reproduction in any medium or format, as long as you give appropriate credit to the original author(s) and the source, provide a link to the Creative Commons license and indicate if changes were made.

The images or other third party material in this chapter are included in the chapter's Creative Commons license, unless indicated otherwise in a credit line to the material. If material is not included in the chapter's Creative Commons license and your intended use is not permitted by statutory regulation or exceeds the permitted use, you will need to obtain permission directly from the copyright holder. 